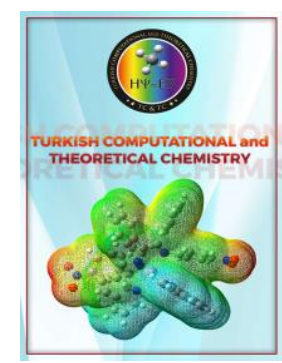

Received: 12.04 .2020
Turkish Computational and Theoretical Chemistry

Turkish Comp Theo Chem (TC\&TC)

Volume(Issue): 4(2) - Year: 2020 - Pages: 59-66

e-ISSN: $2602-3237$

https://doi.org/10.33435/tcandtc. 718807

Accepted: 07.06.2020

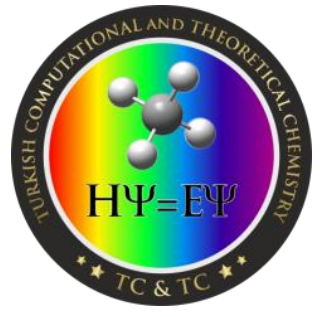

Research Article

\title{
An Optimization and Pharmacokinetic Studies of some Thymidine Derivatives
}

\author{
Sarkar M.A. KAWSAR ${ }^{l, a}$, Mohammed Anowar HOSEN a \\ ${ }^{a}$ Laboratory of Carbohydrate and Nucleoside Chemistry (LCNC), Department of Chemistry, Faculty of \\ Science, University of Chittagong, Chittagong-4331, Bangladesh
}

\begin{abstract}
Thymidine is a predecessor of nucleotides that forms DNA and plays a significant role in cell metabolism and as a co-enzyme. Most of the thymidine analogues have remarkable antiviral activity due to structural functions and are globally used as antiviral drugs. Modification of the hydroxyl (-OH) group of thymidine by acylation may causes changes in the property of thymidine which is investigated in this study. Herein, we relate the optimization of thymidine and its acylated analogues applying density functional theory (DFT) with B3LYP/3-21G level theory to demonstrate their thermal, frontier molecular orbital, the density of states (DOS) and molecular electrostatic potential (MEP) properties. Pharmacokinetic parameters are also enumerated to investigate absorption, metabolism, oral toxicity, and carcinogenicity of thymidine and its modified derivatives.
\end{abstract}

Keywords: Thymidine, DNA, HOMO-LUMO, DOS, MEP, Pharmacokinetic.

\section{Introduction}

Thymidine, structurally known as deoxythymidine (Figure 1) is a pyrimidine based nucleoside that constitutes a major part of one of the four nucleosides in DNA and listed as chemical teratogen [1]. Alteration of the hydroxyl $(-\mathrm{OH})$ group at $3^{\prime}$ and $5^{\prime}$ position changes the activity of thymidine and bring about some lifesaving antiviral drug. Azidothymidine (AZT) is one of the most popular thymidine derivatives (antiviral drugs) in which $3^{\prime}$ hydroxyl (-OH) of thymidine replaced by an azide group and now it's used in worldwide for the treatment of HIV infection [2]. AZT suppresses the mode of reverse transcription, a ticklish phase in the life cycle of the virus. Edoxudine is another thymidine derived antiviral drug, strongly working against herpes simplex virus [1]. Moreover, thymidine is used in cell biology to synchronize cells. Thymidine analog Bromodeoxyuridine is often used for the detection of proliferating cells in living tissues. Thymidine is also catabolised to identify TP-expressing tumor xenografts [3]. In this investigation, modified thymidine derivatives are optimized to realize their thermal, electrical stability, and biochemical behavior based on quantum mechanical methods. Molecular weight, electronic energy, free energy, enthalpy, HOMOLUMO energy gap, dipole moment and polarizability have been predicted to make a comparison of their thermal and chemical characteristic. Finally, the pharmacokinetic prediction has been performed to compare their absorption, metabolism, toxicity, and carcinogenicity. The prime motive of our exploration was to realize the thermodynamic, frontier molecular orbital, electrostatic potential, and ADMET properties.

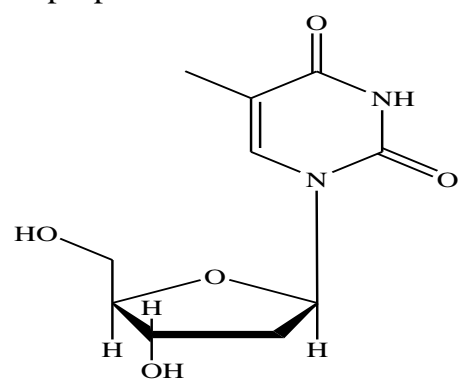

Figure 1. Chemical structure of the thymidine.

\footnotetext{
${ }^{1}$ Corresponding Authors

e-mail: akawsarabe@yahoo.com
} 


\section{Methods of Computational Details}

2.1. Designing and Optimization of Thymidine Derivatives

In computational drug design study, quantum mechanical methods are broadly used to calculate thermal or thermophysical, frontier molecular orbital and molecular electrostatic properties [4]. Gaussian 09 program was employed to carry out computational geometry optimization and also alternation of all thymidine analogues [4]. Density functional theory (DFT) with Beck's (B) [5] threeparameter hybrid model, Lee, Yang, and Parr's (LYP) [6] correlation functional under 3-21g basis set has been employed to optimize and predict their thermal and molecular orbital properties. Molecular weight, electronic energy, enthalpy, free energy, dipole moment and polarizability were calculated for all the compounds. Besides this, electrostatic potential calculated for thymidine and its four derivatives. HOMO (highest occupied molecular orbital) and LUMO (lowest unoccupied molecular orbital) i.e. frontier molecular orbital characteristics were calculated at the same grade of theory of optimization. HOMO-LUMO energy gap, hardness $(\eta)$, and softness $(S)$ were enumerated from the energies of frontier HOMO and LUMO in case of each of the thymidine derivative as reported considering Parr and Pearson interpretation of DFT and Koopmans theorem [7] on the interrelation of electron affinities (E) and ionization energy (I) with HOMO and LUMO transition energy $(\varepsilon)$. The following equations are used to calculate hardness $(\eta)$, softness $(\mathrm{S})$.

$$
\eta=\frac{[\varepsilon L U M O-\varepsilon H O M O]}{2} ; \mathrm{S}=\frac{1}{\eta}
$$

\subsubsection{Strategies and Optimization of} Designed Thymidine Analogues

The new analogues of thymidine used in this study were designated according to the reactions scheme. Thymidine (1) and its derivatives (2-12) were designated and optimized in the quantum mechanical method and Figure 2 shows the optimized structure of thymidine derivatives.

2.2. Pharmacokinetic parameters study (ADMET prediction)

To check the pharmacokinetic parameters and toxicity of the modified thymidine derivatives and parent compound, the admetSAR server was utilized [8]. All the latest and most extensive manually curated data predicted by admetSAR with help of structure uniformity search methods for various chemicals linked with known ADMET schemes.
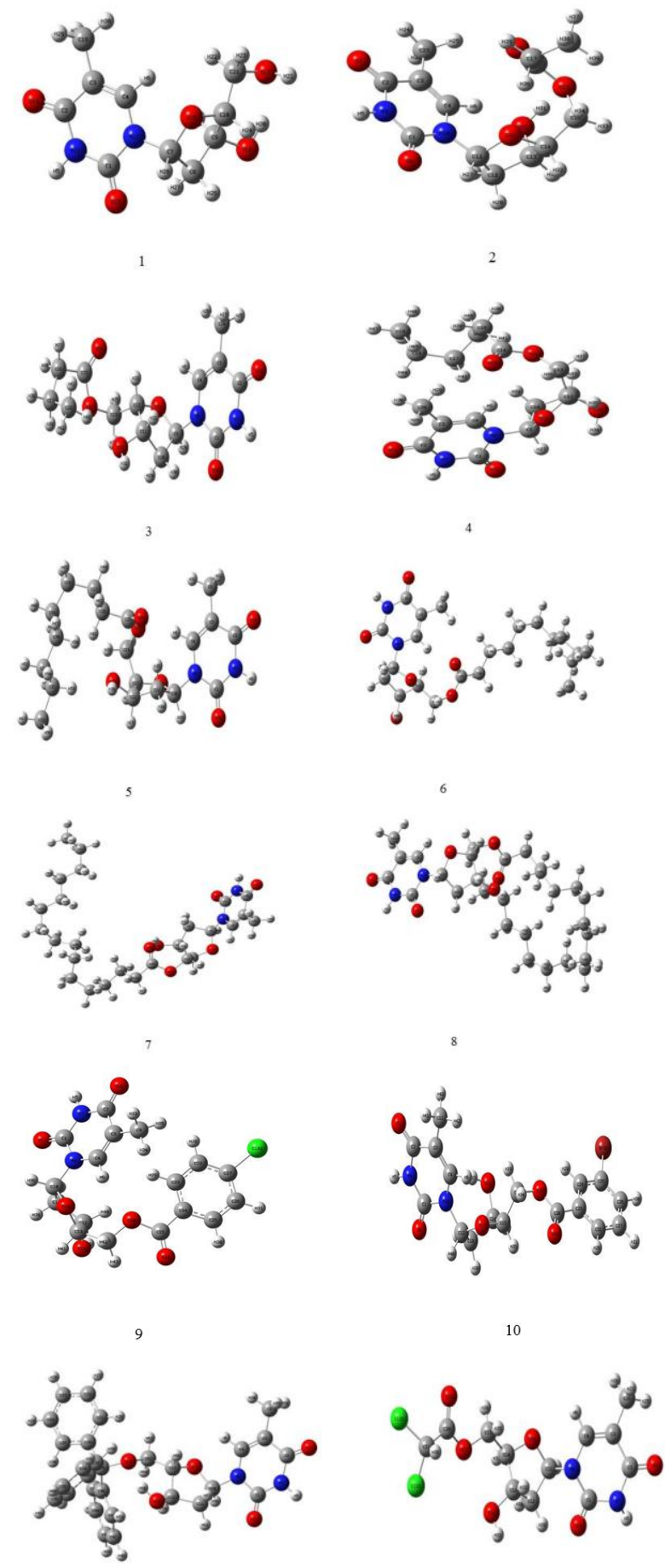

1

Figure 2. Optimized structure of thymidine (1) and its derivatives (2-12). Optimized with 
For ADMET analysis, the admetSAR program was used in which 96000 matchless compounds with 45 types of ADMET-associated parameters, proteins, and organisms have been cautiously curated from a massive number of diverse literature. Although it is quite difficult to verify all of these compounds and to know whether this program included thymidinebased drugs or not, well known Pt-based cisplatin and carboplatin as well as metal-based drugs approved in the FDA and in clinical trials as test candidates to verify our thymidine derivatives.

\subsection{Thermodynamic Analysis}

Usual alterations of the molecular structure significantly influence the structural properties including thermal and molecular orbital parameters. Spontaneously of a reaction and stability of a product can be elucidated from the free energy and enthalpy values [9]. Highly negative values are more suitable for thermal stability. In computational molecular modeling, the dipole moment influences non-bonded interactions hydrogen bond formation smoothly. Binding property can also be improved by the increasing of dipole moment [10].

The highest free energy is (-3773.7669 Hartree) observed for thymidine derivative (10) which also showed the highest enthalpy (-3773.6856 Hartree) and highest electronic energy ( -3773.6866 Hartree). The highest dipole moment is (8.1677 Debye) observed for thymidine derivative (5) whereas (8) shows the highest polarizability (308.2033 a.u.). Presences of a bulky acylating group suggesting the possible improvement of polarizability are presented in Table 1. Remarkable changes observed that, with the increase of molecular weight, electronic energy, enthalpy, free energy, and polarizability are sharply increased from compound (1) to (8) which have a long acyl chain. But in the case of compound (10) which has an aromatic ring highest value was observed.<smiles>Cc1cn(C(O)C(O)CO)c(=O)[nH]c1=O</smiles><smiles>[R]O[C@H](O)[C@H](O)[C@H](O)CO</smiles>

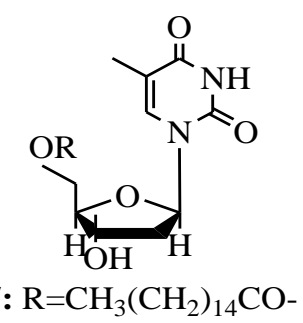

$$
\text { 9: } \mathrm{R}=4-\mathrm{Cl} . \mathrm{C}_{6} \mathrm{H}_{4} \mathrm{CO}-
$$<smiles>[R]C(O)[C@@H](O)OC(=O)n1cc(C)c(=O)[nH]c1=O</smiles>

10: $\mathbf{R}=3-\mathrm{Br} . \mathrm{C}_{6} \mathrm{H}_{4} \mathrm{CO}$ -<smiles>[R20]C[C@H](O)O[C@H]([C@@H](O)CO)n1cc(C)c(=O)[nH]c1=O</smiles><smiles>IC1CCCCC1</smiles>

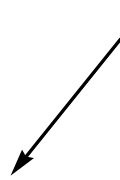

11: $\mathbf{R}=\left(\mathrm{C}_{6} \mathrm{H}_{5}\right)_{3} \mathrm{C}$ -<smiles>[R]O[C@H](O)[C@@H](O)N1C=C(C)C(=O)NN1</smiles>

$12: \mathbf{R}=\mathrm{Cl}_{2} \mathrm{CHCO}$ -
8: $\mathbf{R}=\mathrm{CH}_{3}\left(\mathrm{CH}_{2}\right)_{16} \mathrm{CO}$ -<smiles>Cc1cn(C(=O)O[C@H](O)C(=O)O)c(=O)[nH]c1=O</smiles>

6: $\mathbf{R}=\mathrm{CH}_{3}\left(\mathrm{CH}_{2}\right)_{10} \mathrm{CO}$ -

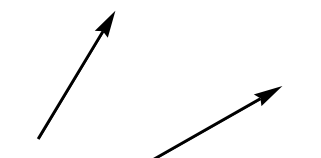<smiles>Cc1cn(C(C(O)O)C(O)O)c(=O)[nH]c1=O</smiles>

5: $\mathbf{R}=\mathrm{CH}_{3}\left(\mathrm{CH}_{2}\right)_{7} \mathrm{CO}-$<smiles>[2H]C[C@@H](O)[C@@H](O)[C@@H](O)Cn1cc(C)c(=O)[nH]c1=O</smiles>

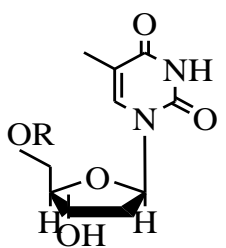

4: $\mathbf{R}=\mathrm{CH}_{3}\left(\mathrm{CH}_{2}\right)_{4} \mathrm{CO}$ -<smiles>Cc1cn(C(C(O)O)C(O)O)c(=O)[nH]c1=O</smiles>

3: $\mathbf{R}=\mathrm{CH}_{3}\left(\mathrm{CH}_{2}\right)_{2} \mathrm{CO}-$

\section{2: $\mathrm{R}=\mathrm{CH}_{3} \mathrm{CH}_{2} \mathrm{CO}$ -}

Figure 3. Chemical structure of the thymidine derivatives (2-12). 
Turkish Comp Theo Chem (TC\&TC), 4(2), (2020), 59-66

Sarkar M.A. KAWSAR, Mohammed Anowar HOSEN

Table 1. Molecular weight (g/mol), Electronic energy, enthalpy, Gibbs free energy in Hartree, dipole moment (Debye) \& polarizability (a.u.) of thymidine derivatives

\begin{tabular}{ccccccc}
\hline Compound & $\begin{array}{c}\text { Molecular } \\
\text { weight }\end{array}$ & $\begin{array}{c}\text { Electronic } \\
\text { Energy }\end{array}$ & Enthalpy & $\begin{array}{c}\text { Gibbs free } \\
\text { Energy }\end{array}$ & $\begin{array}{c}\text { Dipole } \\
\text { moment }\end{array}$ & Polarizability \\
\hline $\mathbf{1}$ & 242.23 & -870.0526 & -870.0516 & -870.1115 & 5.8393 & 120.8300 \\
$\mathbf{2}$ & 298.29 & -1060.9161 & -1060.9152 & -1060.9838 & 7.6814 & 150.8330 \\
$\mathbf{3}$ & 312.12 & -1099.9842 & -1099.9832 & -1100.0578 & 3.6114 & 163.0413 \\
$\mathbf{4}$ & 340.37 & -1178.1264 & -1178.1255 & -1178.2061 & 5.1343 & 180.0320 \\
$\mathbf{5}$ & 382.45 & -1295.3336 & -1295.3326 & -1295.4192 & 8.1677 & 216.2986 \\
$\mathbf{6}$ & 424.53 & -1412.5517 & -1412.5508 & -1412.6522 & 4.6777 & 243.7000 \\
$\mathbf{7}$ & 480.58 & -1568.8237 & -1568.8227 & -1568.9368 & 4.6224 & 287.5253 \\
$\mathbf{8}$ & 508.69 & -1646.9831 & -1646.9822 & -1647.0993 & 4.5303 & 308.2033 \\
$\mathbf{9}$ & 380.78 & -1669.8739 & -1669.8730 & -1669.9533 & 3.5124 & 198.4623 \\
$\mathbf{1 0}$ & 425.23 & -3773.6866 & -3773.6856 & -3773.7669 & 3.2666 & 203.9716 \\
$\mathbf{1 1}$ & 484.54 & -1598.2169 & -1598.2160 & -1598.3110 & 6.8616 & 298.2556 \\
$\mathbf{1 2}$ & 353.16 & -1936.6275 & -1936.6265 & -1936.7016 & 3.2650 & 160.1390 \\
\hline
\end{tabular}

Table 2. Stoichiometry, Energy (eV) of HOMO, LUMO, energy gap, hardness \& softness of analogues

\begin{tabular}{ccccccc}
\hline Compound & Stoichiometry & ${ }^{\varepsilon} \mathrm{HOMO}$ & ${ }^{\varepsilon}$ LUMO & Gap & Hardness $(\eta)$ & Softness (S) \\
\hline $\mathbf{1}$ & $\mathrm{C}_{10} \mathrm{H}_{14} \mathrm{~N}_{2} \mathrm{O}_{5}$ & -6.2868 & -0.7217 & 5.5651 & 2.7826 & 0.3594 \\
$\mathbf{2}$ & $\mathrm{C}_{13} \mathrm{H}_{18} \mathrm{~N}_{2} \mathrm{O}_{6}$ & -6.2185 & -0.5397 & 5.6788 & 2.8394 & 0.3522 \\
$\mathbf{3}$ & $\mathrm{C}_{14} \mathrm{H}_{20} \mathrm{~N}_{2} \mathrm{O}_{6}$ & -6.2395 & -0.7222 & 5.5173 & 2.7587 & 0.3625 \\
$\mathbf{4}$ & $\mathrm{C}_{16} \mathrm{H}_{24} \mathrm{~N}_{2} \mathrm{O}_{6}$ & -6.0256 & -0.6344 & 5.3912 & 2.6956 & 0.3709 \\
$\mathbf{5}$ & $\mathrm{C}_{19} \mathrm{H}_{30} \mathrm{~N}_{2} \mathrm{O}_{6}$ & -5.9214 & -0.4161 & 5.5053 & 2.7527 & 0.3633 \\
$\mathbf{6}$ & $\mathrm{C}_{22} \mathrm{H}_{36} \mathrm{~N}_{2} \mathrm{O}_{6}$ & -6.0063 & -0.5282 & 5.4781 & 2.7390 & 0.3651 \\
$\mathbf{7}$ & $\mathrm{C}_{26} \mathrm{H}_{44} \mathrm{~N}_{2} \mathrm{O}_{6}$ & -6.1842 & -0.7092 & 5.4750 & 2.7375 & 0.3653 \\
$\mathbf{8}$ & $\mathrm{C}_{28} \mathrm{H}_{48} \mathrm{~N}_{2} \mathrm{O}_{6}$ & -6.2204 & -0.7527 & 5.4677 & 2.7338 & 0.3658 \\
$\mathbf{9}$ & $\mathrm{C}_{17} \mathrm{H}_{17} \mathrm{~N}_{2} \mathrm{O}_{6} \mathrm{Cl}$ & -6.2750 & -1.8143 & 4.4607 & 2.2304 & 0.4484 \\
$\mathbf{1 0}$ & $\mathrm{C}_{17} \mathrm{H}_{17} \mathrm{~N}_{2} \mathrm{O}_{6} \mathrm{Br}$ & -6.5154 & -1.6529 & 4.8625 & 2.4313 & 0.4113 \\
$\mathbf{1 1}$ & $\mathrm{C}_{29} \mathrm{H}_{28} \mathrm{~N}_{2} \mathrm{O}_{5}$ & -6.0218 & -0.7386 & 5.2832 & 2.6416 & 0.3785 \\
$\mathbf{1 2}$ & $\mathrm{C}_{12} \mathrm{H}_{14} \mathrm{~N}_{2} \mathrm{O}_{6} \mathrm{Cl}_{2}$ & -6.3965 & -1.7805 & 4.6160 & 2.3080 & 0.4333 \\
\hline
\end{tabular}
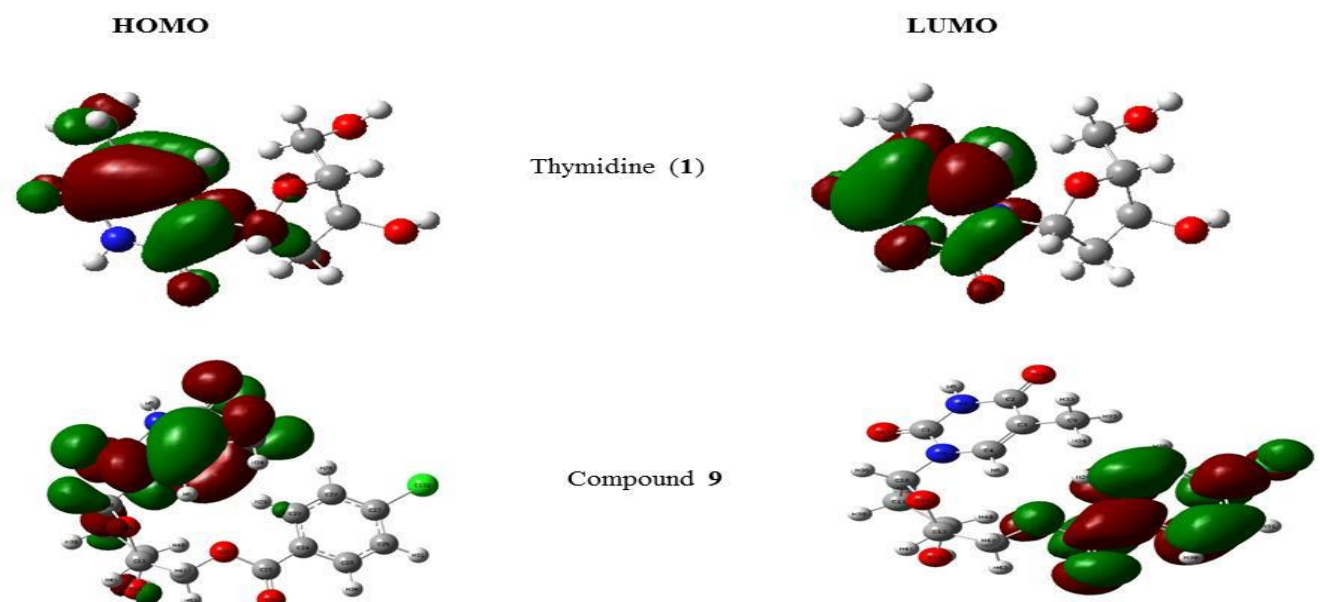

Figure 4. Molecular orbital distribution plots of HOMO \& LUMO of thymidine (1) and its derivative 9. 
Turkish Comp Theo Chem (TC\&TC), 4(2), (2020), 59-66

Sarkar M.A. KAWSAR, Mohammed Anowar HOSEN
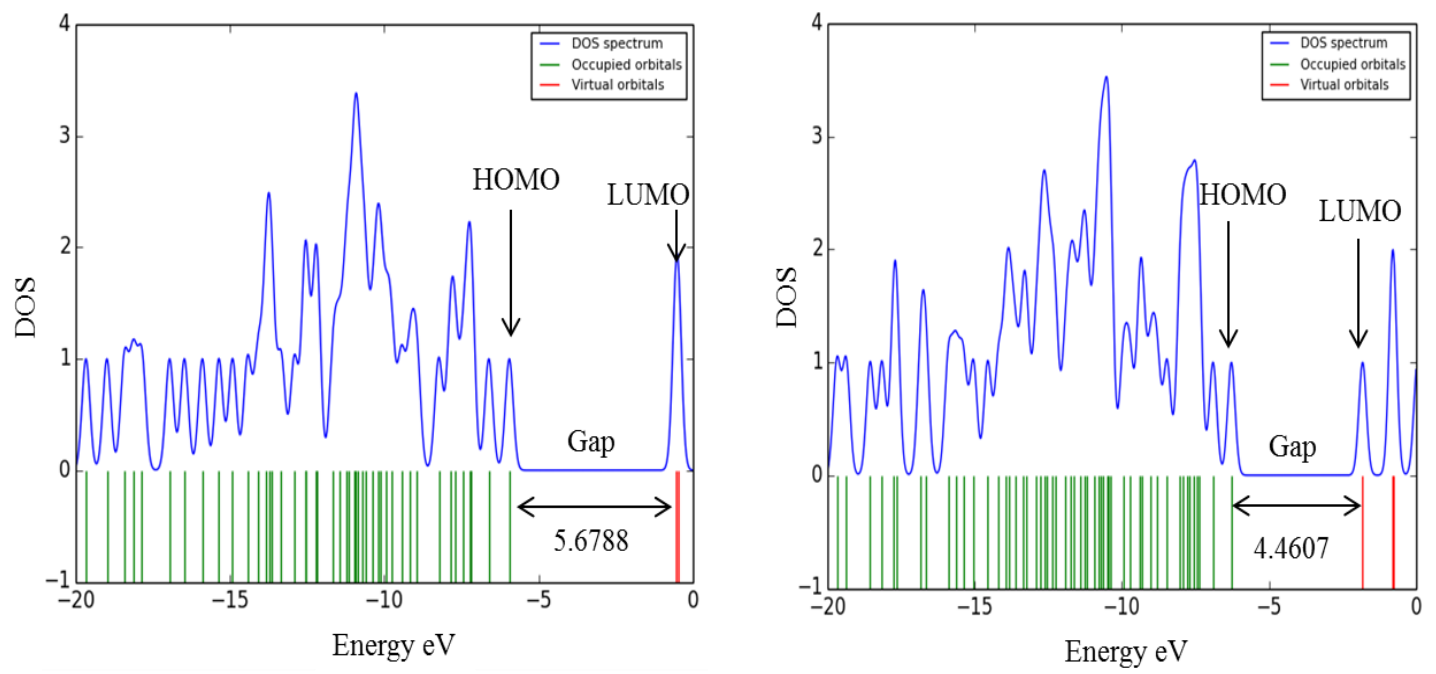

Figure 5. DOS plot and HOMO-LUMO energy gap of the compounds (2) and (9).

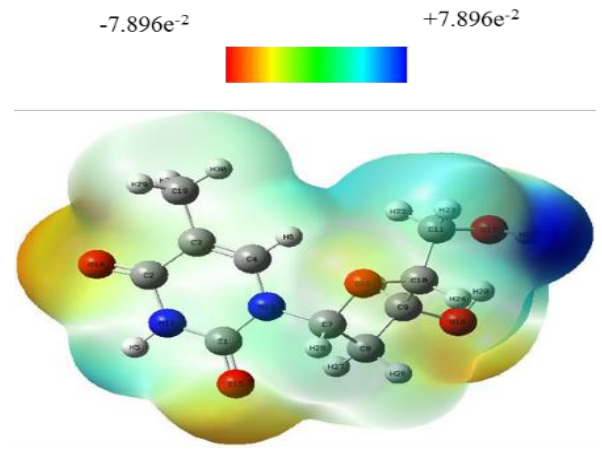

Thymidine (1)
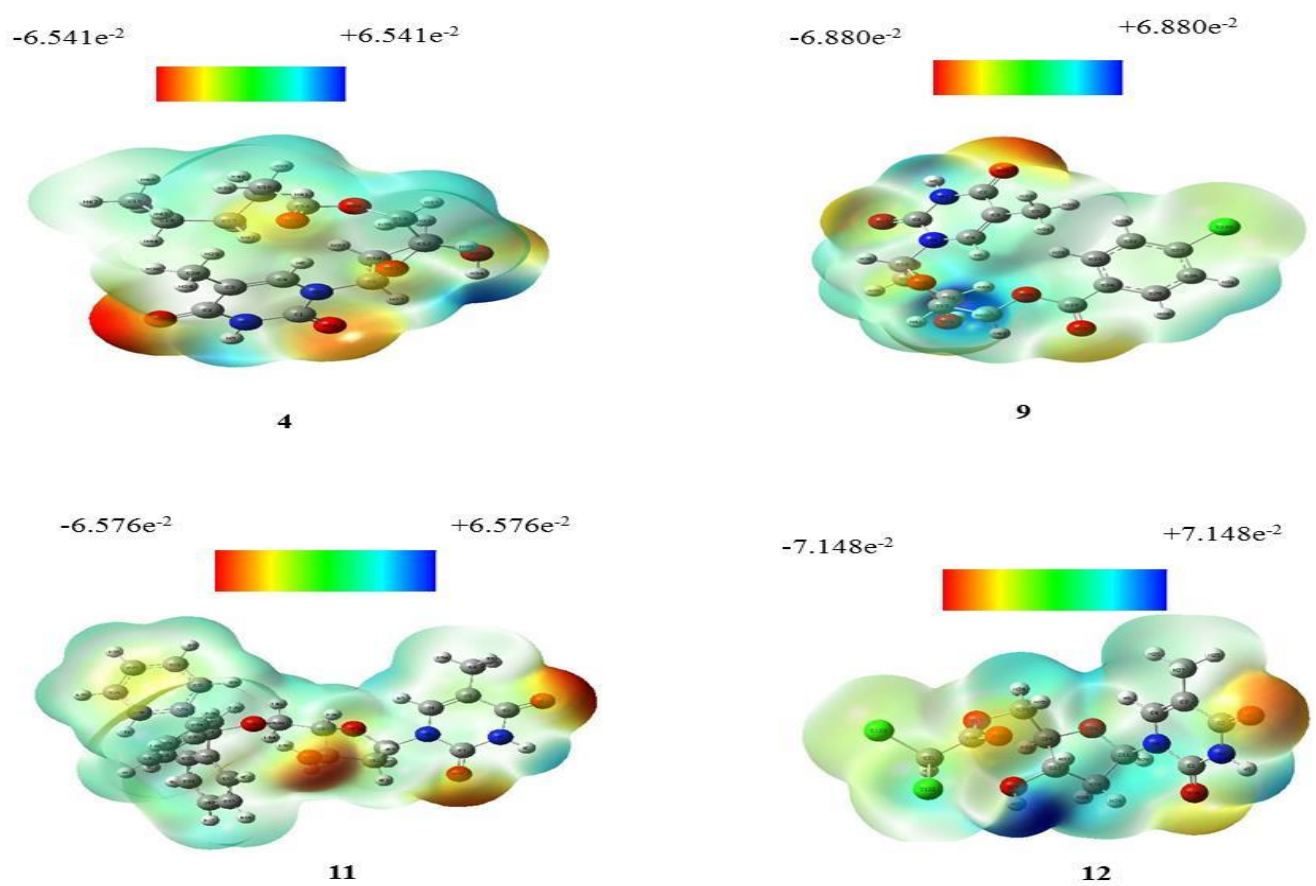

Figure 6. Molecular electrostatic potential map of thymidine derivatives. 
Table 3. Pharmacokinetic properties of thymidine derivatives

\begin{tabular}{cclllll}
\hline $\begin{array}{c}\text { Compound } \\
\text { No. }\end{array}$ & BBB & $\begin{array}{l}\text { Human } \\
\text { intestinal } \\
\text { absorption }\end{array}$ & $\begin{array}{l}\text { P- } \\
\text { glycoprotein } \\
\text { inhibitor }\end{array}$ & hERG & Carcinogen & $\begin{array}{l}\text { Acute } \\
\text { oral } \\
\text { toxicity }\end{array}$ \\
\hline $\mathbf{1}$ & $+(0.9676)$ & $+(0.4294)$ & $\mathrm{NI}(0.9441)$ & $\mathrm{WI}(0.6156)$ & $\mathrm{NC}(0.7000)$ & $\mathrm{III}$ \\
$\mathbf{2}$ & $+(0.9579)$ & $+(0.7527)$ & $\mathrm{NI}(0.7969)$ & $\mathrm{WI}(0.5190)$ & $\mathrm{NC}(0.6857)$ & $\mathrm{III}$ \\
$\mathbf{3}$ & $+(0.9581)$ & $+(0.7527)$ & $\mathrm{NI}(0.7276)$ & $\mathrm{WI}(0.5907)$ & $\mathrm{NC}(0.6857)$ & $\mathrm{III}$ \\
$\mathbf{4}$ & $+(0.9552)$ & $+(0.7527)$ & $\mathrm{NI}(0.6621)$ & $\mathrm{WI}(0.5926)$ & $\mathrm{NC}(0.6857)$ & $\mathrm{III}$ \\
$\mathbf{5}$ & $+(0.9552)$ & $+(0.7527)$ & $\mathrm{NI}(0.4750)$ & $\mathrm{WI}(0.4085)$ & $\mathrm{NC}(0.6857)$ & $\mathrm{III}$ \\
$\mathbf{6}$ & $+(0.9552)$ & $+(0.7527)$ & $\mathrm{NI}(0.4462)$ & $\mathrm{WI}(0.6986)$ & $\mathrm{NC}(0.6857)$ & $\mathrm{III}$ \\
$\mathbf{7}$ & $+(0.9552)$ & $+(0.7527)$ & $\mathrm{NI}(0.6369)$ & $\mathrm{WI}(0.4198)$ & $\mathrm{NC}(0.6857)$ & $\mathrm{III}$ \\
$\mathbf{8}$ & $+(0.9552)$ & $+(0.7527)$ & $\mathrm{NI}(0.6402)$ & $\mathrm{WI}(0.4170)$ & $\mathrm{NC}(0.6857)$ & $\mathrm{III}$ \\
$\mathbf{9}$ & $+(0.9536)$ & $+(0.7904)$ & $\mathrm{NI}(0.5897)$ & $\mathrm{WI}(0.6754)$ & $\mathrm{NC}(0.7429)$ & $\mathrm{III}$ \\
$\mathbf{1 0}$ & $+(0.9517)$ & $+(0.7478)$ & $\mathrm{NI}(0.6216)$ & $\mathrm{WI}(0.6448)$ & $\mathrm{NC}(0.7429)$ & $\mathrm{III}$ \\
$\mathbf{1 1}$ & $+(0.9627)$ & $+(0.7638)$ & $\mathrm{NI}(0.7940)$ & $\mathrm{WI}(0.7845)$ & $\mathrm{NC}(0.7000)$ & $\mathrm{III}$ \\
$\mathbf{1 2}$ & $+(0.9611)$ & $+(0.7521)$ & $\mathrm{NI}(0.7555)$ & $\mathrm{WI}(0.5752)$ & $\mathrm{NC}(0.6286)$ & $\mathrm{III}$ \\
\hline
\end{tabular}

$+=$ Positive, $I=$ Inhibitor, $N I=$ Non-Inhibitor, $W I=$ Weak Inhibitor, $N C=$ Non-Carcinogenic, III = Category III includes compounds with LD50 greater than $500 \mathrm{mg} / \mathrm{kg}$ but less than $5000 \mathrm{mg} / \mathrm{kg}$.

\subsection{Frontier molecular orbitals analysis}

Frontier molecular orbitals are known as important orbitals in a molecule and they are considered to characterize two inherent property i.e. kinetic stability and chemical reactivity. These frontier molecular orbitals are known as the highest occupied molecular orbital (HOMO) and the lowest unoccupied molecular orbital (LUMO) (Figure 4). Table Energy values of frontier orbitals are represented in Table 2 for all the compounds along with the two widely used chemical descriptors parameter, hardness and softness. Compound (9) showed the lowest HOMO-LUMO energy gap, hardness, and highest softness which revealed the molecule has more reactivity than other derivatives, according to Pearson et al [11-12]. In Figure 4 the LUMO plot of the compound (9) showed that the electron was localized at the modified acylating group regions only, while the HOMO plot showed that the electron was localized on the upper part of the thymine ring. The density of states (DOS) plot and HOMO-LUMO energy gap of the compounds (2) and (9) are presented in the Figure 5.

\subsection{Molecular Electrostatic Potential (MEP)}

Molecular electrostatic potential (MEP) is globally preferred as a map of reactivity that exhibits the most probable region for organic molecules to performing electrophilic and nucleophilic reactions of charged point-like reagents [13]. It helps to interpret the biological recognition process and hydrogen bonding interaction [14]. MEP counter map provides a simple way to predict how different geometry could interact. The MEP of the title compound is obtained based on the B3LYP with basis set 3-21G optimized result and shown in Figure 5. The prime significant of MEP is that it simultaneously displays positive, negative, and neutral electrostatic potential regions as well as molecular size, shape by color grading, and very helpful in the study of molecular structure with physicochemical features relationship [15]. Molecular electrostatic potential (MEP) was calculated to forecast the reactive sites for electrophilic and nucleophilic attack of the optimized structure of thymidine derivatives $(4,6$, 11, and 12). The different colors of electrostatic potential indicate different values. Potentiality of attacking zone decreases in the sequence of blue $>$ green $>$ yellow $>$ orange $>$ red. The maximum negative area is displayed by red color where electrophiles can easily attack and the maximum positive area indicated by blue color which is suitable for nucleophilic attack. Moreover, the green color showed the zero potential zones. 


\subsection{ADMET Analysis}

Pharmacokinetic properties have been calculated to compare the absorption, metabolism, and toxicity of all thymidine derivatives. AdmetSAR calculation (Table 3) predicts these thymidine derivatives are non-carcinogenic and possess category III oral toxicity, so thymidine derivatives can be suggested to be relatively harmless for oral administration. All drugs are Pglycoprotein non-inhibitor where P-glycoprotein inhibitor can interrupt the absorption, permeability, and retention of the drugs. All drugs show positivity allowing for the blood-brain barrier. However, all the thymidine derivatives have shown weak inhibitory characteristics for human ether -a gogoRelated Gene (hERG). Inhibitory features of hERG can be led to longer QT symptoms [16], that's why further investigation is required on this aspect.

\section{Conclusion}

To provide an extensive research, the inherent stability and thermophysical properties of thymidine and its modified derivatives are studied. All the modified thymidine derivatives have a lower HOMO-LUMO gap except (2) and have prosperous pharmacokinetic properties than the parent molecule thymidine (1). That's why modified compounds may be considered more reactive than thymidine, as the showed lower HOMO-LUMO gaps. The electrostatic potential map showed probable electrophilic and nucleophilic attacking zone of some thymidine derivatives. ADMET analysis suggested that the modified analogues were less toxic and have improved pharmacokinetic scheme than the parent compound. Finally, this study may be useful to realize the chemical, thermal, electrostatic potential and pharmacokinetic properties of thymidine derivatives.

\section{Acknowledgment}

The authors are very much thankful to the Research Cell, University of Chittagong, Bangladesh for providing financial support to carry out this research project.

\section{References}

[1] Sax, R.J. Lewis, The following list of chemicals known or believed to be teratogens is drawn primarily from dangerous properties of industrial materials, 7th Ed., Wiley, 1988.
[2] A.A. Krayevsky, K.A. Watanabe, Modified Nucleosides as Anti-AIDS Drugs: Current Status and Perspectives, Bioinform, Moscow, (1993) p-211.

[3] S. Tabata, M. Yamamoto, H. Goto, et al., Thymidine Catabolism as a Metabolic Strategy for Cancer Survival. Cell Report 19 (2017) 1313-1321.

[4] R.A. Gaussian09, 1, M.J. Frisch, G.W. Trucks, H.B. Schlegel, G.E. Scuseria, M.A. Robb, J.R. Cheeseman, G. Scalmani, V. Barone, B. Mennucci, G.A. Petersson et al., Gaussian, Inc, Wallingford CT., 2009.

[5] A.D. Becke, Density-functional exchangeenergy approximation with correct asymptotic behaviour. Physical Review A 38 (1988) 3098-3100.

[6] C. Lee, W. Yang, R. G.Parr, Development of the colle-Salvetti correlation-energy formula into a functional of the electron density. Physical Review B 37 (1988) 785-789.

[7] R.G. Pearson, Absolute electronegativity and hardness correlated with molecular orbital theory. Proceedings of the National Academy of Sciences 83 (1986) 8440-8441.

[8] F. Cheng, W. Li, Y. Zhou, J. Shen, Z. Wu, G. Liu, et al (2012) admetSAR: A comprehensive source and free tool for assessment of chemical ADMET properties. Journal of Chemical Information and Modelling 52 (2012) 3099-3105.

[9] N. Cohen, S. W. Benson, Estimation of heats of formation of organic compounds by additivity methods. Chemical Reviews 93 (1993) 2419-2438.

[10] E.J. Lien, Z.R. Guo, R.L. Li, C.T. Su, Use of dipole moment as a parameter in drugreceptor interaction and quantitative structureactivity relationship studies. Journal of Pharmaceutical Sciences 71 (1982) 641-655.

[11] M.M. Hoque, M.A. Halim, M.G. Sarwar, M. Khan, Palladium-catalyzed cyclization of 2alkynyl- $N$-ethanoyl anilines to indoles: synthesis, structural, spectroscopic, and mechanistic study. Journal of Physical Organic Chemistry 28 (2015) 732-742.

[12] R.G. Parr, Z. Zhou, Absolute hardness: unifying concept for identifying shells and subshells in nuclei, atoms, molecules, and 
Turkish Comp Theo Chem (TC\&TC), 4(2), (2020), 59-66

Sarkar M.A. KAWSAR, Mohammed Anowar HOSEN

metallic clusters. Accounts of Chemical Research 26 (1993) 256-258.

[13] M.L. Amin, P-glycoprotein inhibition for optimal drug delivery. Drug Target Insights 2013 (2013) 27-34.

[14] P. Politzer, J.S. Murray, Molecular electrostatic potentials and chemical reactivity. Reviews in Computational Chemistry 2 (1991) 273-312.
[15] P. Politzer, D.G.Truhlar (Eds.), Chemical applications of atomic and molecular electrostatic potentials, Plenum Press, NY, 1981.

[16] M.C. Sanguinetti, M.T. Firouz, hERG potassium channels and cardiac arrhythmia. Nature 440 (2006) 463-469. 